\title{
SINGLE-DOSE PRULIFLOXACIN VERSUS SINGLE-DOSE PEFLOXACIN IN THE TREATMENT OF ACUTE UNCOMPLICATED URINARY TRACT INFECTION IN WOMEN
}

\author{
M. CERVIGNI ${ }^{1}$, G. ORTICELLI ${ }^{2}$, M. BOLOGNA ${ }^{1}$, F. NATALE $^{1}$, E. SALVATORI ${ }^{2}$, G. $^{2}$ \\ DI LORETO2 ${ }^{2}$ P. DIONISIO ${ }^{2}$
}

1 SAN CARLO HOSPITAL, UROGYNAECOLOGICAL UNIT - ROME, ITALY

2 A.C.R.A.F. S.P.A., MEDICAL DEPARTMENT - ROME, ITALY

Keywords: Prulifloxacin, pefloxacin, single-dose, acute uncomplicated UTIS

\begin{abstract}
SUMMARY: The aim of the study was to compare the efficacy and safety of singledose prulifloxacin vs. single-dose pefloxacin in the treatment of patients with acute uncomplicated urinary tract infections. Two bundred and thirty-one female out-patients were considered microbiologically evaluable and randomly treated with 600 $\mathrm{mg}$ prulifloxacin (116 patients) or $800 \mathrm{mg}$ pefloxacin (115 patients). The most commonly isolated uropathogen at baseline was Escherichia coli (71.4\%), followed by Proteus mirabilis (10.8\%) and Klebsiella pneumoniae (7.8\%). Five-seven days posttreatment, the eradication rate was $97.4 \%$ and $92.2 \%$ in the prulifloxacin and pefloxacin group, respectively. The one-tailed 95\% confidence interval analysis showed the equivalence of treatments. Four weeks from treatment no relapses, reinfections or superinfections were observed. The clinical success rates were $92.2 \%$ in the prulifloxacin and $84.3 \%$ pefloxacin groups. The safety profile was very good with both drugs. The results of the study make it possible to consider prulifloxacin a possible therapeutic option in patients with acute uncomplicated UTIS.
\end{abstract}




\section{INTRODUCTION}

It was estimated that $20-30 \%$ of adult women experience one or more episodes of dysuria yearly, and most of these episodes represent acute uncomplicated cystitis (1). The diagnostic and therapeutic approaches of acute uncomplicated urinary tract infection (UTI), a common disorder in premenopausal women, have recently been better defined.

The correlation of the patient's history and physical examination with urinalysis (including the nitrite dipstick and leukocyte esterase test) was usually sufficient to diagnose UTIs (2) and, although urine culture remains the diagnostic golden standard, a specific combination of symptoms (i.e. dysuria and frequency without vaginal discharge) raises the probability of a correct diagnosis of acute uncomplicated UTI based on history alone to more than 90\% (3). Adequate diagnostic strategies may lead to a more accurate use of therapy, thereby reducing the cost of managing cystitis without increasing adverse events or decreasing patient satisfaction (4).

Since Grüneberg and Brumfitt conducted the first single-dose clinical trial in 1967, a large number of studies have shown the efficacy of singledose antibacterial treatment of acute cystitis in women $(5,6)$. Single-dose or short-term (3-day) therapeutic regimens are attractive as they ensure compliance, reduce costs, have less impact on the normal fecal and vaginal flora and possibly decrease the emergence of resistant organisms.

The role of fluoroquinolones in the treatment of UTIs has also been clari- fied: nowadays, they are considered the first-line treatment of acute uncomplicated cystitis in patients who cannot tolerate sulfonamides or trimethoprim, who live in areas with known resistance to trimethoprim-sulfamethoxazole (TMP-SMX) or who have risk factors for such resistance (7). In this context, single-dose treatments could have clear advantages over longer ones, as shown in clinical trials performed with pefloxacin and ciprofloxacin comparing single-dose versus multiday therapies $(8,9)$. Short-term therapy can be considered the treatment of choice in premenopausal women with acute uncomplicated cystitis because of similar effectiveness, better tolerance and compliance, and lower cost compared to conventional therapy (10).

Prulifloxacin (AF3012 or NM441), a new quinolonic antibacterial agent prodrug of AF3013 (or NM394), extensively investigated in Europe and in Japan for the treatment of respiratory and urinary tract infections (11), has a wide spectrum of antibacterial activity against Gram-negative and Gram-positive strains comparable to or higher than that of other reference drugs $(12,13,14)$.

After oral administration, prulifloxacin is transformed by a paroxonase into the active compound (15), and is then distributed to the tissues maintaining sustained urinary concentration for over 48 hours, due to its favourable kinetic profile in terms of an extensive renal excretion and long elimination half-life (10 hours). The broad antibacterial spectrum and the prolonged urinary concentrations of prulifloxacin are ideal for its use in single-dose administration. 
A multicenter, controlled clinical trial was performed to compare the efficacy and safety of two single-dose treatments, $600 \mathrm{mg}$ prulifloxacin versus $800 \mathrm{mg}$ pefloxacin in women with acute uncomplicated UTIs.

\section{MATERIALS AND METHODS}

This was a phase III, multicentre, randomised, controlled study vs. pefloxacin, carried out at 6 Italian experimental centres in accordance with the requirements of Good Clinical Practices. The study protocol was approved by the Ethics Committees and all patients provided written informed consent before participating in the study.

Female out-patients diagnosed with acute uncomplicated UTI were considered eligible if they had bacteriuria (defined as the presence of uropathogenic strains in amount $\geq 10$ $\mathrm{cfu} / \mathrm{ml}$, susceptible or moderately susceptible to prulifloxacin and pefloxacin), pyuria (WBC $\geq 10 / \mathrm{mm}^{3}$ in unspun urine examined in a counting chamber or $\mathrm{WBC} \geq 5 / \mathrm{HPF}$ in the resuspended sediment of a centrifuged aliquot of urine) and any combination of dysuria, urgency, frequency and suprapubic pain lasting for less than 10 days $(16,17)$.

Exclusion criteria were recurrent cystitis, pyelonephritis, complicated UTIs, or fever $>37.5{ }^{\circ} \mathrm{C}$; pregnancy and lactation; allergy to study drugs; history of altered cerebral conditions; liver or renal insufficiency; administration of xanthines, fenbufen, antibiotics or antibacterials within the two previous weeks.

Patients were screened and ran- domly assigned to treatments (one prulifloxacin $600 \mathrm{mg}$ tablet or two 400 mg pefloxacin tablets) and assessed at baseline, after 5-7 days (follow-up 1) and 4 weeks after the end of treatment (follow-up 2), by medical history, clinical and laboratory evaluations, including urine culture obtained by mid-micturition urine samples collected using the clean-catch technique.

The identification and susceptibility testing for isolated microrganisms in the urine were performed according to the National Committee for Clinical Laboratory Standards (19). Breakpoints for susceptibility and resistance to prulifloxacin were $1 \mathrm{mg} / \mathrm{ml}$ or less and $4 \mathrm{mg} / \mathrm{ml}$ or more, respectively.

The primary efficacy parameter was microbiological eradication of infecting strains, and the secondary parameter was clinical cure/improvement.

The microbiological response was based on the results of urine cultures performed at follow-up 1 and 2. Bacterial eradication was considered successful when no bacteria was isolated or at concentrations $<10^{3} \mathrm{cfu} / \mathrm{ml}$; the presence of $\geq 103 \mathrm{cfu} / \mathrm{ml}$ bacteria at any time was considered treatment failure. Failure may be due to persistence (the original uropathogen was still present at follow-up 1), relapse (the original uropathogen, not detected at follow-up 1, reappeared at follow-up 2) or superinfection/reinfection (a new uropathogen was found at concentrations $\geq 105 \mathrm{cfu} / \mathrm{ml}$ ).

Patients were defined as clinically cured (in case of resolution of all baseline symptoms), improved (decrease in intensity of all symptoms) or failed (no decrease in the intensity of at least one symptom detected at baseline). Clinical 
cure and improvement were considered a therapeutic success.

Safety was monitored by clinical and laboratory observations. Adverse events were classified according to the COSTART dictionary and tabulated by body system, severity (mild, moderate, severe) and correlation to the therapy (certain, probable, possible, uncertain, unrelated).

\section{Statistical analysis}

The sample size was calculated to demonstrate the equivalence between the two treatments by a non-inferiority trial (19). Assuming a clinical cure rate of $90 \%$ for pefloxacin, a one-tailed confidence level of $95 \%$, a power of $80 \%$ and fixing a threshold of $-15 \%$ for the difference in the proportion of success between the two treatments (prulifloxacin minus pefloxacin), a sample size of 100 patients per group was required, including an expected drop-out rate of $25 \%$.

Efficacy analysis was performed on the Intention To Treat (ITT) population defined as all randomized patients except for patients with sterile basal urine. Tolerability evaluations were performed on all treated patients.

Homogeneity of baseline data and patients' characteristics were assessed by analysis of variance for continuous variables and the chi-square test for categorical variables. The equivalence hypothesis was evaluated by calculating the one-tailed 95\% confidence interval for the difference between the efficacy rates of the two treatments.

\section{RESULTS}

A total of 239 Caucasian female patients were randomized: 121 received prulifloxacin $600 \mathrm{mg}$ and 118 pefloxacin $800 \mathrm{mg}$. Characteristics of patients are summarized in Table I. The ITT population consisted of $231 \mathrm{pa}$ tients (the 239 minus 8 patients who were excluded due to sterile urine samples at baseline).

Baseline variables, including symptoms, signs, and urine culture analysis did not show significant differences between groups. Two hundred and thirty-one causative bacterial strains were identified. No patients had multiple pathogens. The most commonly isolated uropathogen was Escherichia coli (71.4\%), followed by Proteus mirabilis (10.8\%) and Klebsiella pneumoniae (7.8\%). Among all the isolated pathogens, 8 were resistant to pefloxacin, 1 to prulifloxacin and 1 to both drugs. Patients with resistant

\section{Table I - Characteristics of patients}

\begin{tabular}{lccc}
\hline & & $\begin{array}{c}\text { prulifloxacin } \\
(\mathbf{n = 1 2 1})\end{array}$ & $\begin{array}{c}\text { pefloxacin } \\
(\mathbf{n = 1 1 8})\end{array}$ \\
\hline Age (mean \pm S.D.) & years & $36.05 \pm 11.33$ & $37.33 \pm 11.88$ \\
\hline Weight (mean \pm S.D.) & $\mathrm{kg}$ & $63.45 \pm 10.09$ & $64.63 \pm 11.37$ \\
\hline Duration of the episode (mean \pm S.D.) & days & $2.64 \pm 2.16$ & $2.31 \pm 1.43$ \\
\hline
\end{tabular}


Table II - Microbiological and clinical outcomes at follow-up 1 and 2.

\begin{tabular}{|c|c|c|c|c|}
\hline & \multicolumn{2}{|c|}{ Microbiological results } & \multicolumn{2}{|c|}{ Clinical results } \\
\hline & prulifloxacin & pefloxacin & prulifloxacin & pefloxacin \\
\hline \multicolumn{5}{|l|}{ Follow-up 1} \\
\hline Success / total patients & $113 / 116$ & $106 / 115$ & $107 / 116$ & $97 / 115$ \\
\hline Percentage (95\% CI) & $\begin{array}{c}97.4 \\
(94.5 \text { to } 100)\end{array}$ & $\begin{array}{c}92.2 \\
(87.3 \text { to } 97.1)\end{array}$ & $\begin{array}{c}92.2 \\
(87.4 \text { to } 97.1)\end{array}$ & $\begin{array}{c}84.3 \\
(77.7 \text { to } 91.0)\end{array}$ \\
\hline $\begin{array}{l}\text { Mean difference } \\
\text { (one-tailed 95\% CI) }\end{array}$ & \multicolumn{2}{|c|}{5.2} & \multicolumn{2}{|c|}{7.9} \\
\hline
\end{tabular}

\section{Follow-up 2}

\begin{tabular}{lcccc}
\hline Success / total patients & $115 / 116$ & $111 / 114$ & $113 / 116$ & $110 / 114$ \\
\hline Percentage (95\% CI) & $\begin{array}{c}99.1 \\
(97.4 \text { to 100) }\end{array}$ & $\begin{array}{c}97.4 \\
(94.4 \text { to 100) }\end{array}$ & $\begin{array}{c}97.4 \\
(94.5 \text { to 100) }\end{array}$ & $\begin{array}{c}96.5 \\
\text { (93.1 to 99.9) }\end{array}$ \\
\hline $\begin{array}{l}\text { Mean difference } \\
\text { (one-tailed 95\% CI) }\end{array}$ & \multicolumn{2}{c}{$\begin{array}{c}1.8 \\
(-1.1 \text { to 4.6) }\end{array}$} & $\begin{array}{c}0.9 \\
(-2.8 \text { to 4.6) }\end{array}$ \\
\hline
\end{tabular}

strains were equally distributed between treatment groups ( 5 patients in each group).

At follow-up 1 (5-7 days post-treatment), eradication of the infecting uropathogen was achieved in $97.4 \%$ and $92.2 \%$ of patients in the prulifloxacin and pefloxacin group, respectively (Table II). The one-tailed 95\% confidence interval analysis showed the equivalence of treatments. Among the small number of patients $(\mathrm{n}=12)$ who experienced microbiological failure 5-7 days after treatment, no superinfections but only persistences were observed.

The bacteriological success in isolated uropathogens slightly varied across the treatment groups (Table III). It should be noted that after prulifloxacin treatment, all the strains of Pseudomonas sp. were eradicated.

At follow-up 2, no relapses, reinfections or superinfections were observed in patients with a bacteriological response of eradication at 5-7 days after treatment.

The clinical success rates were $92.2 \%$ in the prulifloxacin and $84.3 \%$ pefloxacin groups (Table II). The equivalence hypothesis was demonstrated for the clinical outcome as well. The percentages of clinically cured and improved patients were $61.2 \%(71 / 116)$ and $31.0 \%(36 / 116)$ in the prulifloxacin group, and 54.8\% (63/115) and 29.6\% (34/115) in the pefloxacin group, respectively. The reason for clinical failure was the persistence, with respect to baseline, of one or more symptoms 
without improvement.

At follow-up 2, three patients (1 in the pefloxacin group, and 2 in the prulifloxacin group) did not show sustained cure with respect to follow-up 1 due to the re-appearance of symptoms, although in absence of urinary infection.

No serious adverse events or dropouts due to adverse events were observed. One patient treated with pefloxacin reported mild headache but the correlation with treatment was excluded. Two patients treated with prulifloxacin reported two episodes of mild gastric pain, judged as being probably treatment-related in one case, and uncertain in the other.

The tolerability of prulifloxacin was very good. No significant differences in vital signs from baseline or changes in clinical haematology or chemistry were observed.

\section{DISCUSSION}

The results of this study indicate that a single $600 \mathrm{mg}$ dose of prulifloxacin is at least as effective as pefloxacin $800 \mathrm{mg}$ in the treatment of patients with acute uncomplicated lower UTI, ensuring, as expected, a very good safety profile.

The statistical analysis performed on the ITT population after 5-7 days post-treatment showed the equivalence of treatments, the rate of microbiological eradication being $92.2 \%$ and $97.4 \%$ (mean difference $5.2 ; 95 \%$ C.I. 0.5 to 10.0) in the pefloxacin and prulifloxacin group, respectively, and the rate of clinically cured patients 84.3\% and 92.2\% (mean difference 7.9; 95\% C.I. 1 to 14.8 ), respectively.

Four weeks after treatment, no relapses, reinfections or superinfections were observed in bacteriologically eradicated patients. Probably this interesting outcome is partially related to the use of very strict inclusion/exclusion criteria which favour a correct diagnostic approach, preventing the enrollment of patients with recurrent or complicated cystitis. The accurate as-

Table III - Bacteriological response after 5-7 days post-treatment (follow-up 1) by pretreatment bacterial uropathogens

\begin{tabular}{lcc}
\hline & prulifloxacin & pefloxacin \\
\hline Escherichia coli & $82 / 84(97.6)$ & $78 / 81(96.3)$ \\
\hline Proteus sp. & $14 / 14(100)$ & $11 / 12(91.7)$ \\
\hline Klebsiella pneumoniae & $7 / 8(87.5)$ & $8 / 10(80)$ \\
\hline Pseudomonas sp. & $6 / 6(100)$ & $1 / 2(50)$ \\
\hline Others & $4 / 4(100)$ & $8 / 10(80)$ \\
\hline Total & $\mathbf{1 1 3} / \mathbf{1 1 6}(\mathbf{9 7 . 4 )}$ & $\mathbf{1 0 6} / \mathbf{1 1 5}(\mathbf{9 2 . 2 )}$ \\
\hline
\end{tabular}


sessment of signs and symptoms enables the distinction between diagnoses (20), and a systematic differential diagnosis based on clinical history is essential for the successful treatment of patients with acute uncomplicated UTIs.

In the presence of a correct diagnosis, careful thought should be given to the empirical treatment of cystitis in the prevalence of resistance to traditional therapy (i.e. TMP-SMX), as it could be an important risk factor for treatment failure. When the local TMPSMX resistance exceeds 20\%, alternative antimicrobial agents should be considered (21). In these geographic areas, fluoroquinolones could be used as the first-line therapy (7).

The occurrence of resistance to fluroquinolones is generally limited, as confirmed in this study: 10 out of 231 pathogens isolated at baseline (4\%) showed resistance to treatments, mainly against pefloxacin only (8/10). In other recent studies the in vitro resistance to fluroquinolones in the initial cultures was rare $(9,22)$, confirming the high potential bactericidal activity of this class of antimicrobials.

Although the single-dose regimen has raised some concern, many clinical trials with adequate sample sizes and extensive follow-ups demonstrated that single-dose treatment with fluoroqunolones, namely pefloxacin, ciprofloxacin and gatifloxacin, are fully comparable to 3-5-day regimens $(8,9,22)$. Shorter therapies may enhance patient compliance, diminishing drug exposure and the incidence of adverse reactions.

In view of the fact that single-dose therapy with pefloxacin was indicated by the guidelines of the Infectious Diseases Society of America as an emerging candidate for the treatment of cystitis (23), the results of this study make it possible to consider prulifloxacin a therapeutic option in patients with acute uncomplicated UTIs.

Acute uncomplicated cystitis in premenopausal women can be treated effectively by short-term therapy if suitable antibacterial agents and dosage regimens are used. Agents which have been shown to be effective in any short-term regimen should be considered the treatment of choice in patients with acute uncomplicated cystitis.

\section{Acknowledgments}

This work was supported by a grant from A.C.R.A.F. S.p.A (Rome - Italy). We are grateful to all the microbiology laboratories and the physicians that took part in this study for their cooperation.

\section{CORRESPONDING AUTHOR:}

Paolo Dionisio, MD

Medical Department - A.C.R.A.F. S.p.A.

P.le della Stazione snc

00040 S.Palomba, Pomezia (Rome - Italy)

E-mail: rd.dionisio@angelini.it

tel. +390691045314 - fax +39069194333 


\section{REFERENCES}

1 -SANDFORD J.P. :

Urinary tract symptoms in infections.

Ann Rev Med 1975; 26: 485-98.

2 - VALIQUETTE L. :

Urinary tract infections in women.

Can J Urol 2001; 8 Suppl 1: 6-12

3 -BENT S., NALLAMOTHU B.K., SIMEL D.L., FIHN S.D., SAINT S. :

Does this woman have an acute uncomplicated urinary tract infection?

JAMA 2002; 287(20):2701-10

4 -BENT S., SAINT S. :

The optimal use of diagnostic testing in women with acute uncomplicated cystitis.

Am J Med 2002; 113 Suppl 1A: 20S-28S

5 -GRÜNEBERG R.N., BRUMFITT W. :

Single-dose treatment of acute urinary tract infection.

Br Med J 1967; 3: 649-51.

6 - BAILEY R.R. :

Review of published studies on single-dose theraphy of urinary tract infections. Infection 1990; 18 (Suppl 2): 53-6.

7 -SCHAEFFER A.J. :

The expanding role of fluoroquinolones.

Am J Med 2002; 113 Suppl 1A: 45S-54S

8 - VAN BALEN F.A., TOUW-OTTEN F.W., DE MELKER R.A. :

Single-dose pefloxacin versus five-days treatment with norfloxacin in uncomplicated cystitis in women.

J Antimicrob Chemoter 1990; 26: 153-60

9 -AUQUER F., CORDON F., GORINA E., CABALLERO J.C., ADALID C., BATTLE J.: Single-dose ciprofloxacin versus 3 days of norfloxacin in uncomplicated urinary tract infections in women.

Clin Microbiol Infect 2002; 8: 50-4

10 - NABER K.G. :

Short-term therapy of acute uncomplicated cystitis.

Curr Opin Urol 1999; 9(1): 57-64

11 - GRASSI C., SALVATORI E., ROSIGNOLI M.T., DIONISIO P. :

Randomized, double-blind study of prulifloxacin versus ciprofloxacin in

patients with acute exacerbations of chronic bronchitis.

Respiration 2002; 69(3): 217-22

12 - OZAKI M., MATSUDA M., TOMMII Y., KIMURA K., KAZUNO K., KITANO M. : In vitro antibacterial activity of a new quinolone, NM394.

Antimicrob Agents Chemother 1991; 35: 2490-5 
13 - YOSHIDA T., MITSUHASHI S. :

Antibacterial activity of NM394, the active form of prodrug NM441, a new

quinolone. Antimicrob Agents Chemother 1993; 37: 793-800

14 - MONTANARI M.P., MINGOIA M., VARALDO P.E. :

In vitro antibacterial activity of AF3013, the active metabolite of prulifloxacin against nosocomial and community Italian isolates.

Antimicrob Agents Chemother 2001; 45(12): 3616-22

15 - TOUGOU K., NAKAMURA A., WATANABE S., OKUYAMA Y., MORINO A. : Paraxonase has a major role in the bydrolysis of prulifloxacin (NM441), a prodrug of a new antibacterial agent.

Drug Metab Dispos 1998; 26: 355-59

16 - RUBIN R.H., SHAPIRO E.D., ANDRIOLE V.T., DAVIS R.J., STAMM W.E. : Evaluation of new anti-infective drugs for the treatment of urinary tract infection. Infectious Diseases Society of America and the Food and Drug Administration.

Clin Infect Dis 1992; 15 Suppl 1: S216-27

17 - KUNIN C.M. :

Guidelines for the evaluation of new anti-infective drugs for the treatment of urinary tract infection: additional considerations.

Clin Infect Dis 1992; 15(6): 1041-4

18 - NATIONAL COMMITTEE FOR CLINICAL LABORATORY STANDARD : Performance Standards for Antimicrobial Disk Susceptibility Tests.

Sixth Edition: Approved Standard M2-A6. NCCLS Wayne, Pennsylvania, 1997

19 - COMMITTEE FOR PROPRIETARY MEDICINAL PRODUCTS :

Points to consider on switching between superiority and non-inferiority.

CPMP/EWP/482/99, London, 27 July 2000

20 - WAGENLEHNER F.M., NABER K.G. :

Uncomplicated urinary tract infections in women.

Curr Opin Urol 2001; 11(1):49-53

21 - GUPTA K., HOOTON T.M., STAMM W.E. :

Increasing antimicrobial resistance and the management of uncomplicated community-acquired urinary tract infections.

Ann Intern Med 2001; 135(1):41-50

22 - RICHARD G.A., MATHEW C.P., KIRSTEIN J.M., ORCHARD D., YANG J.Y. : Single-dose fluoroquinolone therapy of acute uncomplicated urinary tract infection in women: results from a randomized, double-blind, multicenter trial comparing single-dose to 3-day fluoroquinolone regimens.

Urology 2002; 59(3):334-9

23 - WARREN J.W., ABRUTYN E., HEBEL J.R., JOHNSON J.R., SCHAEFFER A.J., STAMM W.E. :

Guidelines for antimicrobial treatment of uncomplicated acute bacterial cystitis and acute pyelonephritis in women. Infectious Diseases Society of America (IDSA).

Clin Infect Dis 1999; 29(4):745-58 